\title{
EFEKTIFITAS MENGUNYAH BUAH APEL DAN BUAH BENGKOANG TERHADAP PENURUNAN INDEKS PLAK PADA MURID SEKOLAH DASAR
}

\section{(The effectiveness of chewing apples and yam fruit against decreasing plaque index a child in elementary school children)}

\author{
Cut Aja Nurasiki ${ }^{*}$, Amiruddin ${ }^{2}$ \\ 1,2 Jurusan Keperawatan Gigi, Politeknik Kesehatan Kemenkes Aceh. E-mail: cutaja82@ yahoo.co.id
}

Received: $19 / 3 / 2017$

Accepted: 2/6/2017

Published online: 3/11/2017

\begin{abstract}
ABSTRAK
Karies merupakan suatu penyakit yang disebabkan interaksi antara bakteri debris dan plak, diet serta gii. Pencegahan karies disertai dengan peningkatan kesehatan gigi telah menjadi tujuan utama dalam dunia keperawatan gigi sejak diketahui debris dan plak gigi merukakan faktor yang mendominasi penyebab karies gigi. Berdasarkan hasil yang diperiksa pada 10 anak 7 diatranya berkatagori plak buruk, dan 3 sedang. Tujuan penelitian ideks plak pada murid SD Negeri 1 Tanjung Kecamatan Lhoknga Aceh Besar Tahun 2016. Jenis Penelitian eksperimen semu dgn rancangan pretest and post-test group design. Rancangan Penelitian ini dengan menggunakan dua kelompok subyek kelompok I mengkonsumsi buah apel dan kelompk II mengkonsumsi buah bengkoang yang berjumlah 160 orang. Hasil penelitian 160 orang murid SD Negeri 1 Tanjung sebelum mengunyah apel 1,59 dan sesudah menurun 0,74. Sedangkan sebelum menunyah bengkoang 1,71 dan sesudah 1,06. Terdapat perbedaan signifikan antara sebelum dan sesudah mengunyah apel p=0,000. Kesimpulannya mengunyah buah apel mempunyai efek yang lebih baik dibandingkan mengunyah bengkuang terhadap penurunan indek plak pada murid SD.
\end{abstract}

Kata kunci: Buah apel dan bengkuang, karies gigi, plaks

\begin{abstract}
Caries is a disease caused by the interaction between debris bacteria and plaque, diet and gii. Prevention of caries accompanied by improvement of dental health has become a major goal in the world of dental nursing since it is known debris and dental plaque factor that dominates the cause of dental caries. Based on the results examined on 10 children 7 diatranya berkatagori plaque bad, and 3 medium. The purpose of the study of plaque idaks in elementary school students 1 Tanjung District Lhoknga Aceh Besar. Type of quasi-experimental research with pretest and post-test group design. The design of this study using two groups of subjects group I consumed apples and kelompk II consumed bengkoang fruit which amounted to 160 people. Results of a study of 160 students before
\end{abstract}

chewing apples 1.59 and after decreasing 0.74. While before chewing bengkoang 1.71 and after 1.06. There were significant differences between before and after chewing apples $p=0,000$. The conclusion that chewing apples has a better effect than chewing bengkoang on decreasing plaque index in elementary school students.

Keywords: Apple fruit and yam, dental caries, plaque

\section{PENDAHULUAN}

Karies merupakan suatu penyakit yang disebabkan interaksi antara bakteri, debris dan plak, diet, serta gigi. Pencegahan karies disertai peningkatan kesehatan gigi telah menjadi tujuan utama dalam dunia keperawatan gigi sejak diketahui debris dan plak gigi merupakan faktor yang mendominasi penyebab karies gigi. Plak adalah lapisan tipis yang tak berwarna (transparan) tidak dapat dilihat dengan mata biasa, melekat pada gigi dan membentuk koloni atau kumpulan yang terdiri dari air liur, sisa-sisa makanan, jaringan mati, fibrinogen, mikroorganisme dan lain sebagainya. ${ }^{1,2,3}$

Laporan Survei Kesehatan Rumah Tangga (SKRT) menyatakan, prevalensi penyakit gigi dan mulut meliputi $60 \%$ penduduk. Penyakit gigi yang banyak diderita masyarakat adalah karies dan penyakit periodontal. Sedangkan berdasarkan SKRT-SURKESNAS 2001 menunjukkan bahwa $62,4 \%$ penduduk merasa terganggu pekerjaannya atau murid sekolah tidak masuk sekolah dengan alasan karena sakit gigi. ${ }^{4,5}$

Makanan berserat dan kesehatan mulut yang baik merupakan factor penting dalam

*Penulis untuk korespondensi: cutaja82@yahoo.co.id 
pencegahan penyakit gigi dan mulut. Makanan berserat adalah makanan yang mempunyai daya pembersih gigi yang baik, Seperti nanas, pir, apel, stroberi, papaya, semangka dan bengkoang mengandung banyak air. Apel disebut sebagian kalangan sebagai sikat gigi alami karena dapat dijadikan sebagai pembersih gigi dari sisa-sisa makanan yang masih tertinggal di dalam mulut. Buah apel membantu untuk merangsang gusi, meningkatkan aliran air liur di mulut dan mencegah penumpukan plak pada permukaan gigi. Ditambah lagi, apel sarat akan berbagai vitamin dan mineral. Kandungan dalam apel yang bermanfaat bagi kesehatan gigi dan mulut adalah tannin. Zat tannin ini merupakan zat yang berfungsi membersihkan dan menyegarkan mulut, sehingga dapat mencegah kerusakan gigi dan penyakit gusi yang disebabkan oleh timbunan plak. Selain itu apel juga mengandung asam maleat, yang dapat membersihkan warna gigi yang kusam. ${ }^{6,7}$

Salah satu cara mudah untuk mencegah karies gigi adalah mengatur pola makan dengan memperbanyak mengkonsumsi makanan berserat seperti sayur sawi, wortel dan buah buah-buahan seperti papaya, apel, bengkoang karna mempunyai daya pembersih gigi yang baik membersihkan gigi dari penyebab karies. $^{8}$ Makanan yang bersifat seperti pada nanas, apel, stroberi, papaya, bengkoang mengandung banyak air dan serat, serta kaya dengan gizi. ${ }^{9}$ Bengkoang (pachyrhizus erosus (L) Urban kaya dengan gizi seperti vitamin C, B1, B3, fosfor, zat besi dan kalsium Selain kaya dengan gizi bengkoang juga membersihkan sisa-sisa makanan di celah gigi. ${ }^{10}$

Hasil penelitian Bela ${ }^{11}$, menyatakan buah berserat seperti semangka, melon, pir sangat efektif dalam menurunkan indeks plas pada gigi, terbukti sebelum mengunyah buah 2,30 indeks plak, sesudah mengunyah buah 0,39 memiliki indeks plak baik pada gigi. Hasil penelitian Hidayati ${ }^{12}$, menunjukkan mengunyah buah apel dapat menurunkan indeks Plak, sebelum mengunyah buah apel indeks plak 1,77 dengan kriteria sedang dan sesudah mengunyah buah apel indeks plak 0,80 dengan kriteria baik.
Pada pemeriksaan awal di SD Negeri 1 Tanjung Kecamatan Lhoknga Kabupaten. Aceh Besar tahun 2016 ditemukan plak, dari 10 yang di periksa, 7 diantaranya berkatagori plak buruk, dan 3 anak plak sedang. Menurut data yang didapat, sekolah ini belum pernah di berikan penyuluhan. Pengetahuan anak tentang pemeliharaan gigi dan mulut sangat buruk. Hal ini menyebabkan kebersihan gigi dan mulut siswa/i buruk.

Tannin dalam buah apel dapat mencegah kerusakan gigi dan penyakit gusi. Zat tannin berfungsi membersihkan dan menyegarkan mulut, Selain itu apel juga mengandung asam maleat, yang dapat membersihkan warna gigi yang kusam. ${ }^{13}$ Berdasarkan penelitian yang telah dilakukan diketahui bahwa buang bengkoang memiliki efek mekanis yang dapat menurunkan indeks plak gigi.

\section{DESAIN PENELITIAN}

Jenis penelitian yang digunakan adalah quasi eksperiment dengan rancangan pre-test and post-test only group design untuk membandingkan efektifitas mengkonsumsi buah apel dan bengkoang dengan cara mengunyah pada murid SD Negeri 1 Tanjung. Lokasi ini dipilih karena letaknya sangat strategs jalan Banda Aceh Lhoknga dan mudah dijangkau sebelumnya ditempat ini tidak pernah dilakukan penelitian. Sedangkan waktu penelitian yaitu dilaksanakan mulai dari bulan Maret sampai bulan Juli 2016.

Populasi dalam penelitian ini adalah seluruh murid SDN 1 Tanjung Kecamatan Lhoknga Kabupaten Aceh Besar berjumlah 100 orang. Sampel penelitian adalah seluruh populasi atau total populasi murid SD Negeri 1 Tanjung berjumlah 100 orang.

Data yang dikumpulkan dalam penelitian ini adalah data primer dan data sekunder. Data primer, data yang diperoleh dari pemeriksaan langsung pada pasien, tentang Indeks plak yang diambil dengan teknik pemeriksaan langsung ke dalam mulut murid. Data Sekunder Merupakan data yang diperoleh melalui studi pendahuluan, propel sekolah dan laporan dari dinas terkait. 
Analisis hasil data dalam penelitian ini menggunakan uji T-Test independen untuk menguji pengaruh mengunyah buah apel dan buah bengkoang terhadap penurunan indeks plak dan T-Test independen untuk menguji ada tidaknya perbedaan yang signifikan indeks plak terhadap siswa/i yang mengunyah buah apel dan mengunyah buah bengkuang.

\section{HASIL DAN PEMBAHASAN}

\section{Karakteristik Sampel}

Sampel dalam penelitian ini merupakan murid SDN 1 Tanjung Kecamatan Lhoknga
Kabupaten Aceh Besar yang berjumlah sebanyak 160 orang selanjutnya dibagi kedalam dua kelompok yaitu kelompok. Berikut ini disajikan karakteristik sampel meliputi jenis kelamin, umur, dan kelas.

Berdasarkan tabel 1, terlihat bahwa gambaran karakteristik sampel menurut kelompok perlakuan yang terdiri dari jenis kelamin, umur dan kelas murid SD. Menurut jenis kelamin pada kelompok perlakuan mengunyah Apel lebih banyak laki-laki $(52,5 \%)$, sebaliknya pada kelompok perlakuan mengunyah Bengkoang lebih banyak berjenis kelamin perempuan $(74,5 \%)$.

Tabel 1. Karakteristik sampel menurut kelompok perlakuan

\begin{tabular}{lcccc}
\hline \multirow{2}{*}{ Karakteristik Sampel } & \multicolumn{2}{c}{$\begin{array}{c}\text { Perlakuan mengunyah } \\
\text { Apel }\end{array}$} & \multicolumn{2}{c}{$\begin{array}{c}\text { Perlakuan mengunyah } \\
\text { Bengkoang }\end{array}$} \\
\cline { 2 - 5 } & $\mathrm{n}$ & $\%$ & $\mathrm{n}$ & $\%$ \\
\hline Jenis Kelamin & & & & \\
Laki-laki & 42 & 52,5 & 22 & 25,5 \\
Perempuan & 38 & 47,5 & 58 & 74,5 \\
\hline Umur & & & & \\
6 tahun & 28 & 35,0 & - & - \\
7 tahun & 23 & 28,8 & - & - \\
8 tahun & 29 & 36,3 & - & - \\
9 tahun & - & - & 26 & 32,5 \\
10 tahun & - & - & 28 & 35,0 \\
11 tahun & - & - & 26 & 32,5 \\
\hline Kelas & & & & - \\
I & 30 & 37,4 & - & - \\
II & 25 & 31,3 & - & - \\
III & 25 & 31,3 & - & 33,8 \\
IV & - & - & 27 & 33,8 \\
V & - & - & 27 & 32,4 \\
VI & - & - & 26 & $\mathbf{1 0 0 , 0}$ \\
\hline Jumlah & $\mathbf{8 0}$ & $\mathbf{1 0 0 , 0}$ & $\mathbf{8 0}$ & \\
\hline
\end{tabular}

Begitu juga dengan umur sampel, pada kelompok perlakuan mengunyah Apel mempunyai umur antara 6 sampai 8 tahun dan hampir tidak menunjukan perbedaan proporsi yang begitu nyata. Sedangkan pada kelompok perlakuan mengunyah Bengkoang mempunyai umur antara 9 sampai 11 tahun, dan juga mempunyai proporsi relatif sama. Berdasarkan kelasnya, juga terlihat bahwa murid pada kelas I sampai III dijadikan smpel untuk kelompok perlakuan mengunyah Apel, sedangkan beberapa murid dengan kelas IV sampai dengan kelas VI masuk dalam kelompok perlakuan mengunyah Bengkoang.

\section{Indeks Plaks dengan Mengunyah Buah Apel dan Bengkuang}

Secara deskriptif indeks plak antara sebelum mengunyah Apel dengan setelah mengunyah Apel terlihat bahwa sebelum murid 
SD N1 mengunyah Apel hasil pemeriksaan terhadap indeks plak menunjukan rata-rata yaitu 1,59 dengan deviasi sebesar 0,697. Terlihat juga secara umum indeks plak murid SD berkisar antara 1 sampai dengan 2. Selanjutnya setelah dilakukan perlakuan yaitu dengan memberikan buah Apel (100 g) untuk dikunyah, menunjukan penurunan rerata indeks plak pada murid SD N1 Tajong yaitu 0,74 dengan deviasi sebesar 0,466 . Secara umum, setelah mengunyak buah Apel indeks plak murid SD lebih banyak menurun yaitu dibawah 1. Secara statistik, untuk menjawab hipotesis yang diajukan maka digunakan uji statistik Paired T-Test.
Berdasarkan hasil uji statistik (tabel 2) diperoleh selisih rerata indeks plak antara sebelum dengan setelah mengunyak Apel yaitu 0,85 dengan deviasi 0,553 , nilai selisih rerata berada pada rentang indeks plaks lower $(0,73)$ dengan upper $(0,97)$ sehingga Ho ditolak dan Ha diterima ( $\mathrm{p}$-value $<0,000)$. Kesimpulannya yaitu terdapat perbedaan indeks plak antara sebelum mengunyah Apel dengan setelah mengunyah Apel pada murid SDN 1 Tanjong Kecamatan Lhoknga Aceh Besar. Dengan makna yang lain, bahwa mengunyah Apel sebanyak $100 \mathrm{~g}$ dapat menurunkan indeks plak gigi pada murid SD.

Tabel 2. Hasil statistik pengaruh mengunyah Apel dan Bengkuang terhadap indeks plak $(n=80)$

\begin{tabular}{lcccc}
\hline \multicolumn{1}{c}{ Indeks Plak } & Rerata \pm SD & Selisih rerata \pm SD & CI: 95\% & p-value \\
\hline $\begin{array}{l}\text { Sebelum mengunyah } \\
\text { Apel }\end{array}$ & $1,59 \pm 0,657$ & $0,85 \pm 0,553$ & 0,73 s.d 0,97 & 0,000 \\
$\begin{array}{l}\text { Setelah mengunyah } \\
\text { Apel }\end{array}$ & $0,74 \pm 0,466$ & & & \\
\hline $\begin{array}{l}\text { Sebelum mengunyah } \\
\text { Bengkoang }\end{array}$ & $1,71 \pm 0,670$ & $0,64 \pm 0,608$ & 0,51 s.d 0,78 & 0,000 \\
$\begin{array}{l}\text { Setelah mengunyah } \\
\text { Bengkoang }\end{array}$ & $1,06 \pm 0,491$ & & & \\
\hline
\end{tabular}

Setelah dilakukan analisis data terhadap indeks plak pada murid atau kelompok yang mengunyah Bengkoang, maka diperoleh hasil sebagaimana disajikan pada gambar 2. Indeks plak sebelum mengunyah Bengkoang (100 g) mempunyai rata-rata 1,71 dengan deviasi sebesar 0,67. Terjadi sedikit penurunan indeks plak setelah mengunyah Bengkoang yaitu dengan rata-rata 1,06 dan deviasi sebesar 0,491. Jika sebelum mengunyah Bengkoang mempunyai indeks plak antara 1 sampai dengan 2, maka setelah mengunyah Bengkoang indeks plak berkisar antara 1 sampai 1,5 pada murid SDN 1 Tanjong Kecamatan Lhoknga Aceh Besar. Berdasarkan tabel 2, diketahui bahwa selisih indeks plak pada gigi antara sebelum dengan setelah mengunyah Bengkoang yaitu 0,64 dengan deviasi 0,608 . Selisih indeks plak gigi berada antara nilai lower 0,51 dan upper 0,78. Hasil statistik juga diperoleh nilai probabilitas yaitu 0,000 sehingga pada CI:95\% Ho ditolak dan Ha diterima. Berdasarkan hasil tersebut dapat disimpulkan bahwa terdapat perbedaan signifikan ( $\mathrm{p}$-value $<0,05)$ indeks plak antara sebelum dengan setelah mengunyah Bengkoang pada gigi murid SDN 1 Tanjong Kecamatan Lhoknga Aceh Besar.

Plak adalah lapisan tipis, lunak, lekat, tidak berwarna dan mengandung bakteri yang terbentuk pada permukaan gigi dan merupakan penyebab utama terjadinya karies (lubang gigi) dan penyakit periodontal. Kecepatan pembentukan palak di pengaruhi leh konsistensi, macam dan kerasnya lunaknya makanan. Ternyata plak banyak terbentuk jika lebih banyak mengkonsumsi makanan lunak terutama makanan yang mengadung karbohidrat jenis sukrosa, karena kan menghasilkan dekstan dan levan yang memegang peranan penting jenis sukrosa dalam pembentukan matrik plak. ${ }^{3}$

Makanan berserat dan kesehatan mulut yang baik merupakan factor penting dalam pencegahan penyakit gigi dan mulut. Makanan berserat adalah makanan yang mempunyai daya 
pembersih gigi yang baik, seperti nanas, pir, apel, stroberi, papaya, semangka dan bengkoang mengandung banyak air buah apel membantu untuk merangsang gusi, meningkatkan aliran air liur di mulut dan mencegah penumpukan plak pada permukaan gigi. ${ }^{10}$ Ditambah lagi, apel sarat akan berbagai vitamin dan mineral. Kandungan dalam apel yang bermanfaat bagi kesehatan gigi dan mulut adalah tannin. Hal ii juga membuat buah apel miliki kemampuan dapat melakukan seif cleasing terhadap rongga mulut dan menurukan tingkat bakteri dalam mulut serta dapat melindungi gigi dari keropos serta penyakit gusi. ${ }^{12}$

Makanan berserat adalah makann ini dapat membersihkan gigi dari penyebab karies. Makan yang bersifat seperti ini adalah jenis buah- buahan seperti pada apel, nanas, papaya, pir, bengkoang yang banyak mengandug air. ${ }^{14}$

\section{Efektivitas Penurunan Indeks Plak Gigi antara Mengunyah Apel dengan Mengunyah Bengkuang}

Mengunyah apel secara signifikan dapat menurunkan indeks plak pada gigi, begitu juga dengan mengunyah bengkoang. Kedua perlakuan menunjukan pengaruh terhadap penurunan indeks plak gigi pada murid SDN 1 Tanjong Kecamatan Lhoknga Kabupaten Aceh Besar. Walaupun keduanya berpengaruh signifikan, tetapi belum diketahui perlakuan mana yang lebih baik terhadap penuruan indeks plak.

Tabel 3. Hasil statistik efektivitas perlakuan setelahmengunyah Apel dengan mengunyah Bengkoang terhadap indeks plak

\begin{tabular}{lccccc}
\hline \multicolumn{1}{c}{ Indeks Plak } & $\mathrm{n}$ & Rerata $\pm \mathrm{SD}$ & $\begin{array}{c}\text { Perbedaan rerata } \pm \\
\text { CE }\end{array}$ & CI: 95\% & p-value \\
\hline $\begin{array}{l}\text { Mengunyah } \\
\text { Apel }\end{array}$ & 80 & $0,74 \pm 0,466$ & $0,32 \pm 0,076$ & 0,17 s.d0,47 & 0,000 \\
$\begin{array}{l}\text { Mengunyah } \\
\text { Bengkoang }\end{array}$ & 80 & $1,06 \pm 0,491$ & & & \\
\hline
\end{tabular}

Untuk mengukur efektivitas tersebut, maka dilakukan uji statistik yaitu Independent T-Test pada CI:95\%, sebagaimana disajikan pada tabel 3. Tabel 3 adalah membandingkan kedua kelompok perlakuan yaitu setelah mengunyah Apel dengan mengunyah Bengkoang terhadap penurunan indeks plak gigi pada murid SDN 1 Tanjong Kecamatan Lhoknga Aceh Besar. Terlihat bahwa setelah mengunyah Apel $100 \mathrm{~g}$, maka indeks plak mempunyai rata-rata 0,74 dengan deviasi 0,466 sedangkan setelah mengunyah Bengkoang $100 \mathrm{~g}$, rerata indeks plak menjadi 1,06 dengan deviasi sebesar 0,491. Kedua perlakuan mempunyai perbedaan rata-rata sebesar 0,32 dengan nilai standar error sebesar 0,076 yang terletak antara 0,17 sampai dengan 0,47 pada CI:95\%. Hasil uji statistik juga terlihat nilai probabilitas ( $\mathrm{p}$ value) yaitu 0,000 , jadi pada CI:95\% Ho ditolak dan Ha diterima. Kesimpulannya yaitu mengunyah Apel mempunyai efektivitas yang lebih baik (p-value $<0,05)$ dibandingkan mengunyah Bengkoang terhadap penurunan indeks plak gigi pada murid SDN 1 Tanjong Kecamatan Lhoknga Aceh Besar.

Mengunyah apel ternyata mempuyai nilai efektivitas yang lebih baik (p-value 0,05 ) dibandingkan mengunyah bengkoang terhadap perubahan indeks plak gigi pada murid SDN 1 Tanjong Kecamatan Lhoknga Kabupaten Aceh Besar. Hasil tersebut sejalan dengan temuan Aridsandi ${ }^{15}$, salah satu kandugan dalam buah apel adalah tannin, Zat tannin merupakan zat yang berfungsi membersihkan dan menyegarkan mulut, sehingga dapat mencegah kerusakn gigi dan gusi yang disebankan oleh timbunan plak.

Mengkonsumsi buah apel merupakan suatu solusi sebagai salah satu cara yang dapat dilakukan agar kandungan zat tannin dapat bermanfaat langsung bagi kesehatan gigi dan mulut, sehingga akan berdampak signifikan terhadap kesehatan individu. ${ }^{13}$ 


\section{KESIMPULAN}

Indeks plak pada murid SD Negeri 1 Tanjung Lhoknga sebelum mengunyah buah Apel yaitu 1,59 dan setelahnya yaitu menurun sebesar 0,74. Sedangkan sebelum mengunyah buah Bengkoang mempunyai indeks plaks yaitu 1,71 dan setelahnya yaitu menurun sebesar 1,06. Terdapat perbedaan signifikan indeks plak gigi pada murid SD antara sebelum dengan setelah mengunyah buah apel. Selain itu, juga terdapat perbedaan signifikan antara sebelum dengan setelah mengunyah buah bengkoang. Mengunyah apel mempunyai efektivitas yang lebih baik dibandingkan mengunyah bengkoang terhadap penurunan indeks plak gigi pada murid SDNegeri 1 Tanjong Kecamatan Lhoknga Aceh Besar.

Saran, diharapkan kepada siswa SDN I Tanjung Kecamatan Lhoknga dalam partisipasi menjaga kesehatan gii dan mulut, dan agar tetap menjaga gigi dengan cara menyikat gigi, memakan buah yang beserserat. Selain itu, diharapkan agar dilaksanakan penelitian yang lebih lanjut di SDN 1 Tanjung Lhoknga mengkonsumsi makanan berserat terhadap penurunan ideksplak, sehingga kesehatan gigi dan mulut yang optimal.

\section{KEPUSTAKAAN}

1. Djokowidodo D. Jangkauan Pelayanan Kesehatan Gigi dan Mulut di Puskesmas Se Kotamadya Surabaya Tahun 1995 Sampai Dengan Tahun 1997. J Dent Indones. 1999;6(2):13-17.

2. Ahmad J. Aneka Buah dan Khasiatnya. 2010.

3. Hiranya MP, Eliza H, Neneng N. Ilmu Pencegahan Penyakit Jaringan Keras Dan Jaringan Pendukung Gigi. Jakarta: EGC; 2011.

4. Litbangkes RI. Laporan Survei Kesehatan Rumah Tangga (SKRT) 2001: Studi Morbiditas dan Disabilitas. SURKESNAS. 2002;16.

5. Forrest JO. Pencegahan Penyakit Mulut. (Hipokrates, ed.). Jakarta; 1995.
6. Astawan M. Sari Kesehatan Keluarga: Sehat Dengan Buah. Jakarta, Indonesia: PT. Dian Rakyat; 2008.

7. Alhamda S. Status kebersihan gigi dan mulut dengan status karies gigi (kajian pada murid kelompok umur 12 tahun di sekolah dasar negeri kota bukittinggi). Ber Kedokt Masy. 2011;27(2):108.

8. Angela A. Pencegahan primer pada anak yang berisiko karies tinggi (Primary prevention in children with high caries risk). Dent J (Majalah Kedokt Gigi). 2005;38(3):130-134.

9. Al Rahmad AH. Pemberian ASI dan MPASI terhadap Pertumbuhan Bayi Usia 6-24 Bulan. J Kedokt Syiah Kuala. 2017;17(1):814.

10. Syahrizal S. Analisis Kuantitatif Formalin pada Buah Impor pada Swalayan di Kota Banda Aceh. Aceh Nutr J. 2016;1(2):135140.

11. Betri DA. Efektivitas Mengunyah Buah Semangka (Citrullus lanatus) dan Buah Melon (Cucumis Melo L.) Sebagai Self Cleansing Terhadap Penurunan Indeks Debris Anak Usia 8-10 Tahun Di SD Adabiah Kota Padang. 2017.

12. Hidayati S, Suyatmi D. Pengaruh Mengunyah Buah Apel Dan Jambu Biji Merah Terhadap Debris Indeks. J Kesehat Gigi. 2016;3(2):41-46.

13. Dalimartha S, Adrian F. Khasiat Buah Dan Sayur. Jawa Tengah: Penebar Swadaya Grup; 2011.

14. Budisuari MA, Oktarina O, Mikrajab MA. Hubungan pola makan dan kebiasaan menyikat gigi dengan kesehatan gigi dan mulut (karies) di Indonesia. Bul Penelit Sist Kesehat. 2010;13(1 Jan).

15. Arisandi Y, Andriani Y. Pengaruh Makanan Terhadap Kesehatan. Jakarta: Eska Media; 2009. 